\title{
VERSÃo
}

Salome Asega

Homi K.Bhabha

Gregg Bordowitz

Joan Kee

Michele Kuo

Ajay Kurian

Jacolby Satterwhite

\section{Apropriação cultural: uma mesa redonda}

Traduzido por Roberto Cataldo Costa
Artforum, publicado originalmente (C) Artforum, Summer 2017, "Cultural Appropriation: A Roundtable," de Salome Asega, Homi K. Bhabha, Gregg Bordowitz, Joan Kee, Michelle Kuo, Ajay Kurian, e Jacolby Satterwhite. <https://www.artforum.com/inprint/ issue $=201706$ \&id $=68677>$.

Concedido pela Artforum o direito para publicar em português e inglês na Porto Arte: revista de Artes Visuais.

\section{Como citar:}

ASEGA, Salome; BHABHA, Homi K.; BORDOWITZ, Gregg; KEE, Joan; KUO, Michele; KURIAN, Ajay; SATTERWHITE, Jacolby. Apropriação cultural: uma mesa redonda. Porto Arte: Revista de Artes Visuais. Porto Alegre: PPGAV-UFRGS, v. 22, n. 37, p.1-24 jul.-dez. 2017. e-ISSN 2179-8001. DOI: http://dx.doi. org/10.22456/2179-8001.80138 


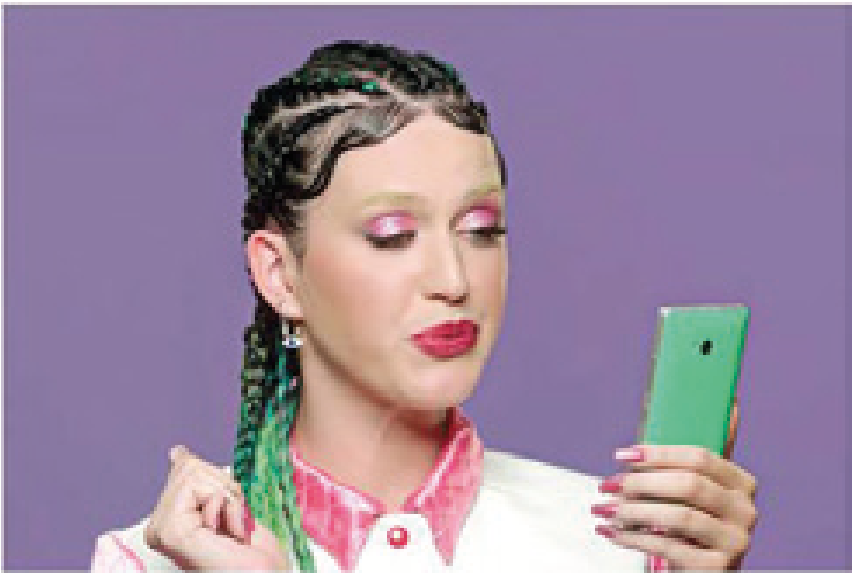

Figura 1. Imagem do vídeo de Katy Perry em 2014, This Is How We Do, dirigido por Joel Kefali. Fonte: $<$ https://www. a r t forum.com/inprint/ issue $=201706$ \&id $=68677>$.

\section{HOMI BHABHA:}

Comecemos com uma proposta: eu prefiro tradução em vez de apropriação. O processo de tradução é um processo de interpretação, de relocalização - de produção, como diz Walter Benjamin, "em outro lugar, algo novo, que mostra o rastro de" - não vou chamá-lo de "o original", mas sim de o anterior, o anterior sem ordem de prioridade. A tradução pressupõe a existência de um estado anterior - seja um texto, um momento histórico anterior ou uma identidade anterior, ou seja, existe algo anterior ao que é traduzido. Diferentemente da apropriação, a tradução é uma relação que não atribui imediatamente um valor padrão a algum tipo de original: o anterior não é visto como o texto "apropriado" ou "original".

Evitando essas premissas padrão, podemos realmente começar a entender se achamos ou não que a apropriação, em qualquer situação, dada é justa ou injusta, ou imprecisa, insultante, provocativa, problemática ou reducionista.

\section{AJAY KURIAN:}

Em nível conceitual, eu concordo com a substituição de apropriação por tradução. Mas quando mudamos a expressão apropriação cultural para tradução cultural, de que forma muda o significado? O que se perde pelo caminho?

\section{JACOLBY SATTERWHITE:}

A apropriação cultural está tendo este momento de trending hashtag, e mesmo assim é uma expressão que está se tornando obsoleta.

As crianças já não aprendem mais vernáculos locais. Essa mudança já tem pelo menos algumas décadas. Na minha infância e na minha juventude em Columbia, na Carolina do Sul, eu aprendi determinados passos de dança na loja da esquina, a uma quadra da minha casa. Os negros de todo o país, de alguma forma, tiveram as mesmas influências. Mas a situação agora é mais extrema. 
Agora, jovens nascidos depois de 1998 simplesmente não reconhecem distinções regionais; eles reconhecem tutoriais e imitam passos de dança, vlogs, podcasts, que podem vir de qualquer lugar. Quando eu tinha quatorze anos, eu ia para casa e assistia os meus DVDs de Madonna, Janet e Sade, e os estudava todos os dias. Tenho certeza de que os jovens estão fazendo a mesma coisa. É como um mundo fantasioso onde você faz coisas desconhecidas e desconectadas da sua própria experiência.

\section{HOMI BHABHA:}

Se os mesmos passos de dança são aprendidos através do YouTube em Botsuana, depois em Bombaim e mais tarde em outro lugar, isso é uma espécie de representação cultural infecciosa. É interessante que ninguém fale de apropriação até alguém considerar que algo inadequado está acontecendo. $\mathrm{E}$ é só aí, quando alguém faz a acusação de apropriação, que começa uma certa discussão.

\section{SALOME ASEGA:}

Para mim, apropriação é uma palavra que ainda tem valor e ainda parece útil. Estou pensando especificamente em um videogame no qual eu trabalhei com Ali Rosa-Salas, Chrybaby Cozie e outros dançarinos de litefeet, que são uma espécie de guardiões do Harlem Shake. Nós fizemos o videogame logo após a febre da dança Harlem Shake, do Baauer, ter viralizado, e depois que foi lançado, era necessário percorrer páginas e páginas no YouTube para encontrar o Harlem Shake original.

E essa palavra foi muito útil para explicar as nossas motivações, porque nós estávamos descrevendo uma espécie de apagamento que aconteceu por causa de uma estrutura de poder específica. É a única palavra. Tradução e citação não explicam o poder em jogo entre os grupos.

\section{HOMI BHABHA:}

Mas não se pode usar apropriação para todas as formas de intercâmbio cultural ou de intersecção cultural. É uma coisa específica, na minha opinião.

\section{MICHELLE KUO:}

E tradução parece explicar as relações de poder, mas não as caracteriza antecipadamente, como apropriação. Mas quando é apropriado usar apropriação?

\section{JACOLBY SATTERWHITE:}

$\mathrm{Na}$ cultura pop, a apropriação nunca se torna polêmica até que o artista que a está praticando se torne popular ou tenha sucesso. Eu venho observando 
a carreira de Iggy Azalea desde 2007, e no início, sua base de fãs era muito diversificada e ninguém tinha problema com ela quando era alternativa - na verdade, gostar dela era bacana. E então, assim que ela teve uma música em primeiro lugar entre as mais ouvidas... Eu leio colunas de fofocas, então eu vi o momento exato em que seu poder cada vez maior provocou essa difamação.

E o poder, ou a falta dele, também pode ajudar a explicar por que agora há um certo abuso do termo apropriação. Eu acho que muitas pessoas estão estressadas nestes tempos difíceis, e muitas delas querem ter algo próprio.

\section{JOAN KEE:}

Eu acho que uma das óticas da crítica é realmente o marco da propriedade. A palavra apropriação basicamente vem do direito eclesiástico, onde denotava a ideia de que um corpo pode anexar algo em caráter exclusivo. Parece que estamos voltando a essa concepção, que é uma das razões pelas quais eu acho que a apropriação se esgotou, perdeu a utilidade como algo de que falamos em termos de empréstimo, tomada ou tradução. Parece haver mais e mais disputa em torno da apropriação como assunto jurídico, onde a lei é que realmente decide quem usa o quê. E afirmações conflitantes começam a dividir pessoas que, em teoria, deveriam se unir para construir algum tipo de bem comum ao invés de endossar esses modos de pensamento muito formais, que tendem a criar divisões: "este é seu e aquele é meu".

\section{MICHELLE KUO:}

O que reproduz exatamente o tipo de propriedade e autoria que fazem parte da estrutura de poder.

\section{HOMI BHABHA:}

Ao contrário da citação, a apropriação assume um sentido de propriedade: quem possui o quê? Em que sentido eu possuo a minha história ou você possui a sua arte? 0 sentido de propriedade pessoal está relacionado a essa noção de propriedade: quem pode falar por ela se ela pertencer a alguém. Isso torna o termo problemático no seguinte sentido: de modo muito geral, na história da opressão - daqueles que são oprimidos pela discriminação racial, por questões de gênero, colonialismo, violência - os oprimidos são sujeitos de uma determinada história, que se torna, de alguma forma, a sua própria. Essa é a experiência deles. Mas essa experiência também foi criada pelo opressor - então há uma dualidade, no mínimo.

Não se pode dizer que a história do colonialismo, ou da escravidão, é apenas a história dos nativos ou dos escravos, porque sua trágica história, 
em si, foi consequência de uma relação - uma relação violenta, hegemônica, eticamente inaceitável e politicamente opressiva. Todas as formas de opressão, assim como todas as formas de resistência ou todas as formas de autorização de poder, são relacionais. Sobre isso, Frantz Fanon pensou o seguinte: para que a mudança aconteça, ela não passará apenas pela resistência justificada e corajosa daqueles que são oprimidos. Ela também terá que desalojar as posições de hegemonia e opressão.

É por isso que eu acho que não se pode simplesmente possuir a própria história de opressão ou de sofrimento. É claro que essa experiência é específica. É claro que ela cria sua própria linguagem e sua experiência em comum. Ela cria sua própria capacidade de construir uma história. Mas ela deve ser vista em termos de "relacionalidade", de uma história de interações dinâmicas.

\section{GREGG BORDOWITZ:}

Eu tenho 52 anos e estava na faculdade de arte em Nova York quando a apropria-

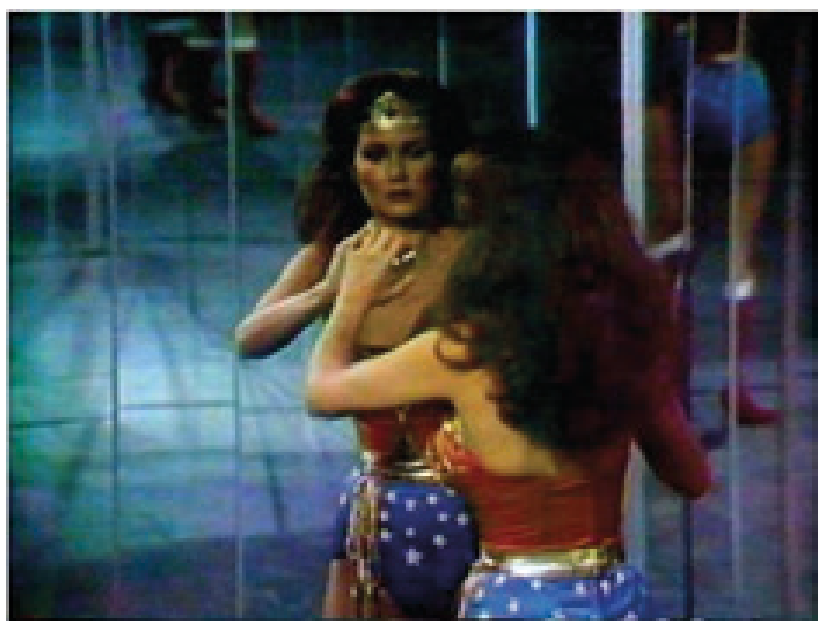

Figura 2. Dara Birnbaum, Tecnology/Transformation: Wonder Woman, 1978-79. Vídeo, cor, som, 5 minutos 50 segundos. Fonte: <https://www. a r t forum.com/inprint/ issue $=201706$ \&id $=68677>$. sobre raça, gênero, sexualidade... Muitas outras conotações se incorporaram ao termo desde que formei minha compreensão inicial sobre ele, talvez limitada.

Em última análise, para nós, naquela época, a questão da apropriação tinha a ver com o material ao qual não tínhamos acesso legal nem tecnológico. Exemplos importantes foram Sherrie Levine, Barbara Kruger, Jenny Holzer e membros da Pictures generation; mas estou pensando especificamente em Dara Birnbaum e no vídeo Technology/Transformation: Wonder Woman [197879], que usava uma cópia da filmagem daquele programa de TV de bastante audiência.

Então, na verdade, apropriação significava roubo, e era uma maneira de reconhecer que a propriedade é roubo e que aqueles que não têm acesso devem se apropriar dos meios de produção e dos materiais da cultura como um ato crítico. Houve muita discussão naquela época sobre os aspectos econômicos, sobre o roubo do rock and roll pela cultura branca, por exemplo, negação de direitos de publicação, injustiças econômicas que tornavam certos autores invisíveis. E ainda há pessoas sendo roubadas monetariamente, pessoas de culturas que não têm acesso a meios de produção. 


\section{JACOLBY SATTERWHITE:}

Então talvez a apropriação possa ser vista como um dispositivo intelectual, mas quando sangra e escorre na cultura de massa, ela se torna outra coisa.

\section{SALOME ASEGA:}

Mas o dispositivo que você está descrevendo é semelhante ao que, digamos, Yellow Jackets Collective ou BUFU estão fazendo...

\section{JACOLBY SATTERWHITE:}

Você quer dizer FUBU?

\section{SALOME ASEGA:}

Não, é um projeto coletivo e multimídia - By Us For Us [Por nós, para nós]. Legalmente, eles não podem usar FUBU porque é marca registrada, então: BUFU-By Us For Us. Esses coletivos de artistas e educadores políticos usam a burla [no original, scamming, NT], em vez de apropriação. E eu sou completamente a favor de burlar, que tem a ver com perceber que, para sobreviver, você deve se apropriar dos signos e da linguagem das pessoas que estão no poder a fim de obter recursos institucionais. Se for uma questão específica de linguagem, eu gosto do termo burlar.

\section{JACOLBY SATTERWHITE:}

Eu também gosto. Podemos chamar este artigo de "Burla"?

\section{HOMI BHABHA:}

Essa noção de burlar sugere que há maneiras melhores de descrever o reposicionamento de ícones culturais ou ideologias. Para mim, esses processos de recontextualização podem ser positivos. Eles podem ser estratégias de resistência. Por exemplo, anos atrás, eu escrevi um ensaio chamado "Sly Civility" [Civilidade ardilosa], que relatava como os missionários cristãos na Índia colonial iam ficando cada vez mais ansiosos quando os índios que aprendiam o inglês e a simbologia do cristianismo começavam a usar essa linguagem. Os missionários diziam: "Agora estamos totalmente perdidos. Não se apropriem da nossa linguagem - nós não sabemos se esses índios estão nos sacaneando ou se eles acreditam no que estamos dizendo. Não conseguimos mais controlá-los".

Eu acho que nós precisamos ter uma maneira positiva de pensar sobre essas atividades, essas estratégias de juntar coisas diferentes, na qual a noção de propriedade seja questionada de alguma forma e se abram algumas novas perspectivas. 


\section{AJAY KURIAN:}

A maior parte da criação cultural atual usa a apropriação em todos esses sentidos diferentes. É praticamente 100\%. Há apropriação, há tradução em tudo.

\section{HOMI BHABHA:}

Eu concordo.

\section{AJAY KURIAN:}

Não há como se evitar, mas talvez eu esteja me concentrando no aspecto negativo exatamente porque o aspecto positivo é algo dado na produção cultural contemporânea no mercado global. O negativo cumpre um papel importante na orientação de possibilidades.

\section{HOMI BHABHA:}

Mas não de forma isolada. "Não tome meus símbolos, não os deturpe no seu trabalho": essas ordens podem ser dadas por qualquer pessoa em todo o espectro político. A apropriação não precisa se dar apenas entre gêneros ou raças. Dentro do mesmo gênero, pode haver apropriações de classe, pode haver apropriações para todos os tipos de propósitos. Isso não significa que um uso político dessas táticas seja intercambiável com outro - cada um precisa ser avaliado em seus próprios termos, e eles são muito mais complicados do que permite o termo apropriação. Precisamos perguntar: Por que você está fazendo isso? Por que está escolhendo fazer essa citação ou sobreposição?

E eu acho que a noção de fazer uma escolha - uma escolha política, uma escolha estética e uma escolha ética - é algo que tem que ser aceito. É importante se ter alguma ideia sobre as maneiras pelas quais podemos usar essas relações interseccionais, intergráficas e intermidiáticas como, mais uma vez, estratégias de resistência que nos permitam tomar algo da casa do senhor de escravos e colocar no lugar do escravo, e produzir algo diferente para ambos.

\section{AJAY KURIAN:}

O outro ponto interessante que você levanta, Homi, é a intencionalidade. É quase como se nós presumíssemos que qualquer pessoa que pratique a cultura e esteja colocando esses símbolos lado a lado esteja consciente do que está fazendo. Mas na verdade, na maioria das vezes, parece que elas ignoram muito o que estão fazendo. Como Katy Perry ou Taylor Swift - há tantos vídeos aos quais a reação é: "Como é que isso aconteceu? Quem foi que viu isso e achou que era uma boa ideia?" Eles fazem parte de uma máquina de mídia que existe para gerar receita, mas, ainda assim, seria de se esperar que houvesse pelo menos mecanismos nominais de contenção, alguém para dizer: "Talvez seja melhor não mexer com isso". 


\section{HOMI BHABHA:}

Você está certo: a questão da intencionalidade é deturpada se for apresentada como um ato plenamente consciente de tradução, interseção, montagem. Nunca poderemos controlar muito esses atos e o que eles significam. Eles excedem a intenção. Por exemplo, o mercado tem múltiplos objetivos - circulação, consumo, reificação, lucro, concorrência, exploração - mas nunca devemos nos esquecer da importância do mercado na criação de dinâmicas interculturais de poder, em tornar certos objetos apropriados e outros, inapropriados, certos objetos visíveis e outros, invisíveis. 0 mercado tem tanto a ver com isso quanto a mídia com a circulação de determinadas formas de representação, determinadas formas de vida, ação e performance.

\section{MICHELLE KUO:}

É isso que impressiona com relação a Dara Birnbaum ou mesmo o Warhol no início, roubando dos meios de comunicação de massa e da televisão comercial em comparação com um músico pop que apenas toma amplamente da cultura como um todo. Mas o que também impressiona é que a indústria cultural tem a maior intencionalidade possível, certo? Eles têm tantos recursos, tanta gente pensando de forma extremamente deliberada sobre o que estão fazendo! $\mathrm{E}$ isso é poder.

\section{GREGG BORDOWITZ:}

Bom, é interessante usar uma expressão como indústria cultural neste momento, assim como o termo apropriação. Isso porque, na verdade, o mundo da arte contemporânea gera tanto capital que está situado em um contínuo com a indústria cultural. Eu não acho que se possa falar de qualquer museu ou acervo sem reconhecer que o chamado mundo da arte, em um nível de alta capitalização, é semelhante ao entretenimento popular. Por exemplo, a Björk ganha uma exposição no Museu de Arte Moderna [em Nova York]. Não estou dizendo nada de ruim sobre Björk ou o MoMA; só estou tentando deixar claro que já não se pode fingir que as belas artes estão de alguma forma fora da indústria cultural.

Devemos distinguir expropriação de apropriação. Expropriação significa tomar a propriedade de alguém. Na teoria de Marx sobre a mais-valia, o valor do trabalho árduo dos trabalhadores é expropriado deles. Apropriação significa tomar algo, como uma imagem, de uma fonte, que talvez pertença a outra pessoa, citando-a, reutilizando-a e lhe dando novo propósito na própria obra de arte. Fora do mundo da arte, um dos mais corajosos atos de apropriação foi a decisão do Brasil de comprar medicamentos contra a AIDS patenteados nos Estados Unidos e na Europa e fazer engenharia reversa para produzir 
versões genéricas de alta qualidade, que foram distribuídas para pessoas com HIV no país. Isso salvou uma enorme quantidade de vidas, e a OMC rejeitou um processo movido por dezenas de grandes empresas farmacêuticas. Foi uma grande vitória. Qual a relação disso com a arte? Os regulamentos da OMC sobre propriedade intelectual incluem fórmulas de medicamentos, bem como produções culturais, como filmes e programas de computador.

Sobre a questão da intencionalidade, eu queria acrescentar que um certo grau de acaso ou escolha inconsciente é inerente à nossa navegação cotidiana na mídia eletrônica e digital que usamos. Se você está apenas surfando em canais a cabo ou indo de uma página do YouTube a outra, o que está fazendo, de muitas maneiras, é participar de uma espécie de acervo aleatorizado de imagens. Basta fazer uma pesquisa de imagens no Google, sobre qualquer termo, e ver o que aparece. Todos nós fazemos isso todos os dias. Os mecanismos de pesquisa possuem algoritmos particularmente prescritivos, e ainda há ocorrências, colisões e sobreposições ocasionais.

\section{MICHELLE KUO:}

Isso remete à questão dos bens comuns, que você levantou, Joan. Muitos de vocês são artistas, talvez considerem as suas obras a mesma coisa que a de Katy Perry, eu não sei. Mas digamos que existam diferentes escalas de produção, mesmo hoje em dia, uma vez que está ficando cada vez mais difícil diferenciar a arte da chamada indústria cultural. 0 que isso

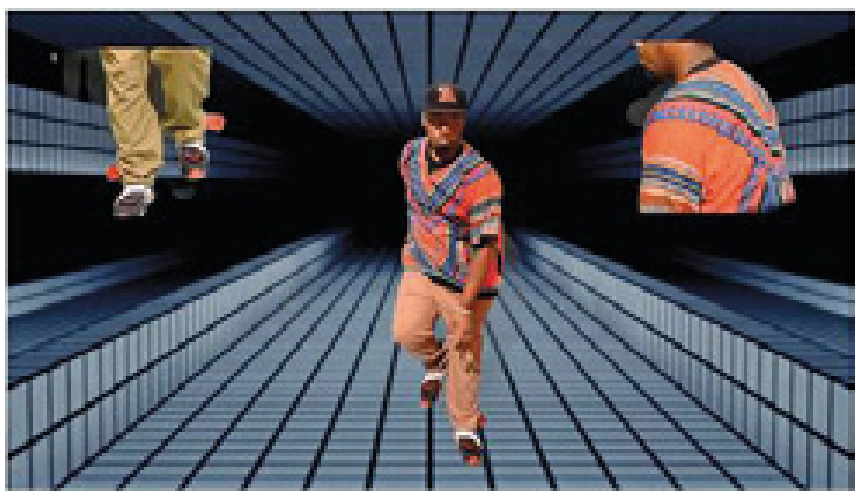

Figura 3. Salome Asega, Ali RosaSalas e Chrybaby Cozie. Level Up: The Real Harlem Shake, 2015. Videogame interativo. Fonte: $<$ https://www. a r t forum.com/inprint/ issue $=201706$ gid $=68677$ >.

\section{JOAN KEE:}

A questão da escala é realmente importante. A ideia dos bens comuns - principalmente no que se refere à reprodução e à tecnologia digitais - dá origem à falácia de que todos têm uma participação igual ou cumprem o mesmo papel na produção e na recepção da cultura. E claro que isso absolutamente não é verdade, porque algumas pessoas têm mais acesso aos recursos do que outras. E então parece que os bens comuns representam realmente sua própria tragédia. Você tem demanda por um determinado recurso, mas todos os que consomem esse recurso prejudicam outros que não têm o mesmo acesso. Então, se parte do objetivo for, digamos, nivelar as escalas de operação, então talvez parte 
do dever de cada indivíduo seja contribuir para o desenvolvimento dos bens comuns, ao invés de simplesmente usufruir infinitamente deles.

\section{HOMI BHABHA:}

Os bens comuns nunca podem ser algo que as pessoas simplesmente consumam. Tem que ser uma relação produtiva e interlocutória. Agora, nem se sabe se é possível nivelar os bens comuns. Pode haver igualdade de um tipo, mas sempre haverá desigualdade de outro. Isto é o que [W. E. B.] Du Bois quis dizer com "pode haver divisões de cor até mesmo dentro de divisões de cor". Muitas vezes, a equalização se transforma em universalização, e temos que ter cuidado com isso porque a universalização é inimiga da especificidade histórica. É inimiga da diferença. 0 melhor que podemos fazer ao definir uma comunidade é criar condições nas quais as pessoas possam concretizar sua agência, o que Amartya Sen chamou de capacidades.

\section{GREGG BORDOWITZ:}

Eu sempre pensei nos bens comuns como um ideal que existe em oposição ao mercado. Os bens comuns são um lugar de contestação, uma tentativa de manter uma noção sobre o que é público - uma noção liberal e burguesa de público que na verdade poderia ter nos servido bem, apesar das contradições do liberalismo.

Eu acho que a coisa mais radical que uma obra de arte pode fazer é constituir um novo público, um grupo de pessoas que nunca se imaginaram sentadas na mesma sala. Esse ainda é o potencial radical da arte - essa capacidade de estabelecer o que costumamos chamar de coalizões ou alianças ou afinidades através das fronteiras da diferença, de constituir novos públicos de interesse, em vez de apelar para um grupo demográfico. Os públicos têm interesses; os grupos demográficos são grupos de consumidores. E esses públicos podem se sobrepor, coexistir - em outras palavras, eles nos permitem conceituar um público que não seja monolítico, onde diferentes grupos de pessoas possam ter participações diferentes nesses debates incrivelmente pesados.

Pessoalmente, eu não consigo imaginar que possamos formular uma proposição universal que nos leve a sair dessas tensões, porque a sociedade está repleta das desigualdades que Joan e Homi mencionaram. A resposta não vai surgir de qualquer polêmica específica do mundo da arte. É muito maior do que isso.

\section{JACOLBY SATTERWHITE:}

Eu acho que esses debates vão desaparecer com as gerações. O novo adolescente de treze anos está absurdamente distante dos problemas de que estamos 
falando. Da maneira como a cultura está sendo divulgada, é claro que somos uns velhos contemplando algo que acabará desaparecendo.

\section{MICHELLE KUO:}

Eu me perguntava se algumas das polêmicas ocorridas no mundo da arte nos últimos dois anos... A geração de jovens de treze anos é mistificada por tudo isso?

\section{SALOME ASEGA:}

Você acha que é?

\section{MICHELLE KUO:}

Eu não sei.

\section{SALOME ASEGA:}

Estou pensando em Amandla Stenberg.

\section{MICHELLE KUO:}

Nós nem sabemos quem é essa pessoa porque somos muito velhos! [Ri.]

\section{SALOME ASEGA:}

Amandla Stenberg fez um vídeo de cinco minutos no YouTube que define a apropriação cultural, chamado Don't Cash Crop on My Cornrows [Não lucre com as minhas tranças negras].

\section{JACOLBY SATTERWHITE:}

Eu acho que ela estava dando uma aula básica sobre o que significa apropriação cultural e por que essa apropriação é problemática, mas, como eu disse, no futuro próximo talvez isso não importe, porque haverá uma inteligência na forma como as pessoas integram ideias, simplesmente porque elas nasceram na mesma época do YouTube ou depois. Nos anos 90, uma mulher branca se vestia de gueixa em um vídeo pop e isso era considerado inteligente. Esse não é o ambiente de hoje.

O que eu penso é: "certo, isso é bem polêmico, eu sou uma raivosa política". Mas eu escolho as minhas batalhas com sabedoria porque eu sou artista e tenho um tipo específico de vocabulário na forma como eu trabalho, e ele é muito sincero. Mas acho que, para algumas pessoas, denunciar a apropriação tem a ver com tendências mais do que com um gesto sincero. É parodiar. É como "tranças de negra em uma garota branca", entende? E não é inteligente, é só: "Oh meu Deus, eu estou denunciando isso! Estou usando uma saia curta!" 


\section{SALOME ASEGA:}

Eu entendo totalmente isso, mas então a pergunta que eu devolvo a você é se os jovens viram o vídeo dela, se eles estão aprendendo a policiar dessa forma que você está descrevendo, qual é a linguagem que eles vão usar quando forem mais velhos? Esse debate realmente vai desaparecer?

\section{JACOLBY SATTERWHITE:}

Eu não acho que eles vão usar essa linguagem. Eu acho que eles estão só parodiando isso. Eles vão ler alguns livros e formar seus próprios argumentos sobre o que é apropriação. Neste momento, eles estão apenas parodiando o sofrimento de outra geração. E esse vídeo é apenas um vídeo viralizado falando bobagens e frivolidades, ao qual que não devemos prestar atenção. Esses jovens não estão prestando atenção; eles ainda estão assistindo alguma dança em algum lugar em Bali, e fazendo isso em seu quarto.

\section{GREGG BORDOWITZ:}

Como se julga a sinceridade do sofrimento de alguém? Eu acompanhei a recente polêmica sobre a pintura de [Dana] Schutz (Open Casket [Caixão aberto], 2016), embora não tenha conseguido chegar a nenhuma conclusão. Eu estava confuso. $\mathrm{O}$ debate revisitou argumentos que eu já havia testemunhado antes; as várias posições formaram uma constelação de divergências, cada uma com precedentes históricos. As questões levantadas abordaram problemas não resolvidos e, até agora, aparentemente intratáveis em torno de raça e representação - questões nas quais eu venho pensando há muito tempo.

Uma analogia que me ocorreu foi o movimento para acabar com o uso de imagens racistas e estereotipadas sobre os índios norte-americanas nas logomarcas das equipes esportivas. Talvez essa analogia não seja completamente apropriada à situação em questão, mas há muito tempo eu ouvi um ativista indígena norte-americano dizer: "Que parte de 'ai, que dor' você não entende?" E aquilo realmente me marcou. Eu quero dizer que eu nunca poderia ter a pretensão de julgar a sinceridade do que alguém diz sobre seu próprio sofrimento.

\section{JACOLBY SATTERWHITE:}

A minha geração se sente mais à vontade com isso porque nós somos a geração do grupo focal, das áreas de comentários do YouTube.

\section{JOAN KEE:}

Eu não acho que a expressão da sinceridade agora seja exatamente como era há dez anos, ou dez como anos antes disso. Existem determinados marcos 
dentro dos quais determinados textos ou ideias são considerados mais sinceros ou adquirem mais credibilidade do que outros.

\section{MICHELLE KUO:}

E a indignação da exposição de Kelley Walker em 2016, no Museu de Arte Contemporânea de St. Louis, por exemplo, que incluiu um trabalho conhecido que cita Race Riots [Revoltas raciais], de Warrock, entre outras imagens oriundas de fontes históricas e da cultura pop? Aquilo era obviamente sincero, mas também parecia haver muitos desencontros e mal-entendidos com relação à arte em si, o que, na minha opinião, continua sendo um exame interessante da subjetividade e da tecnologia. Que diferença fazem o meio - fotografia versus pintura, graus de reprodução e transformação - e a identidade autoral?

\section{JACOLBY SATTERWHITE:}

A minha visão é: essa série existiu por uma década e meia, caramba! Esse trabaIho circulou tanto, e ninguém teve um problema com ele. $E$ foi isso que eu quis dizer quando falei que, quando uma pessoa chega a um determinado nível alto de poder, é aí que de repente se percebem as transgressões criativas dela.

\section{AJAY KURIAN:}

Não, eu não concordo. Eu não acho que o que aconteceu foi desencadeado em função de o artista ter conquistado mais poder. As circunstâncias eram muito específicas. Mostrar esse trabalho em Saint Louis, na sequência [das revoltas raciais em] Ferguson e ter a instituição tão mal preparada para lidar com a crítica, o artista tão mal preparado para receber um público que expressasse questões legítimas - estava claro que ia acontecer. A instituição não proporcionou um contexto e o artista não foi participante ativo quando solicitado. Essa é a receita perfeita para um desastre como resultado da incapacidade de escutar.

\section{JACOLBY SATTERWHITE:}

O que não chega a ser surpreendente, porque o discurso da cultura da imagem no momento em que essas obras foram feitas está, de certa forma, distanciado das questões concretas da política de representação, das interseções de representação com identidade, com a experiência vivida do racismo, do sexismo hoje em dia... Quando essas peças foram feitas, outras preocupações estavam em primeiro plano - a ambivalência da imagem, sua circulação, monetização, digitalização - e as preocupações associadas ao mundo da arte dos anos 90 foram postas de lado. E isso foi uma pena - eu não concordo com isso. Mas entendo, contextualmente. 


\section{HOMI BHABHA:}

Isso destaca outra forma na qual o conceito de tradução é útil, eu acho: apropriação e tradução têm diferentes matrizes de tempo e diferentes formas de abordar valor e valor histórico. A tradução pressupõe que haverá mudanças interpretativas ao longo do tempo em relação a um texto ou trabalho anterior, ou a uma coisa que veio antes. É por isso que eu estou chamando de anterior e não original: haverá traduções, haverá transformações. 0 tempo e o deslocamento contribuirão para essas transformações. É como ter um daqueles comprimidos de liberação lenta, nos quais elementos do objeto anterior emergem em diferentes lugares, em momentos diferentes, e constituem coisas diferentes. Então, pensar sobre o anterior - eu sei que soa estranho - é enfatizar a temporalidade do evento, objeto ou ideia, seu lugar no tempo, e não a posse exclusiva do tempo como um momento congelado, imediato ou imóvel.

A tradução também pressupõe que a relação do anterior com a coisa que segue possa ser tangencial. Não precisa ser mimética nem reflexiva. Não é uma relação fundacional. É uma relação vetorial, de modo que o objeto traduzido não é irreconhecível pelo objeto anterior, mas tem suas próprias figurações e configurações e até mesmo deformações e interpretações equivocadas... . É uma intervenção interpretativa.

Então, se você aceita a tradução, o problema não é de continuidade entre o original e o posterior; é de convergência. As coisas vêm de diferentes lugares, por diferentes meios, histórias diferentes, e convergem a um lugar, uma ideia ou uma imagem. Essa convergência se tornará, ela própria, um momento de anterioridade, do qual surgirão outras estruturas ou figuras de tradução e interpretação.

Não quero, de forma alguma, negar a especificidade histórica ou a singularidade cultural de algo que acontece pela primeira vez ou de algo que vive na memória ou na história como uma "cena primitiva", ou algum evento fundacional em torno do qual uma história é construída ou destruída. Reconhecer o caráter de tradução do "original" ou o "autêntico" certamente não é uma forma de pluralismo ou relativismo sem consideração com a agência, o poder ou o conflito. A tradução como uma atividade do anterior enfatiza o que Walter Benjamin chama de "contraste dialético": há um espaço de resistência ou deslocamento, revisão e rearranjo, intervenção e reinterpretação, reinvenção e redescrição, se você procurar o suficiente e refletir por tempo suficiente. Naquele momento, começa o trabaIho de discernimento e escolha: o que é uma apropriação fácil, autoenaltecedora e narcisista? E o que é uma tradução com caráter de busca e questionamento?

\section{GREGG BORDOWITZ:}

Isso retorna ao que Ajay estava dizendo sobre a falta de discurso produtivo: acho que a discussão pública sobre essas questões é extremamente importante. 
Mas eu não quero viver em um mundo onde isso seja legislado, onde o que pode e não pode ser feito seja prescrito pela autoridade.

\section{AJAY KURIAN:}

Não, não pode ser legislado. Mas ninguém está dizendo a Dana Schutz que ela não poderia ter feito a pintura.

\section{MICHELLE KUO:}

Bom, algumas pessoas estavam dizendo isso.

\section{JACOLBY SATTERWHITE:}

As pessoas estão dizendo que ela vai ser destruída, o que eu não gosto. Uma obra de arte nunca deve ser destruída.

\section{GREGG BORDOWITZ:}

Eu não quero ver essas coisas policiadas em nível de lei. Em termos de sentimentos, dor, desencadeantes, os tipos de contextos em que existimos hoje; eu sou muito, muito sensível a essas preocupações como educador. Eu entendo isso da perspectiva de alguém que vê, em primeira mão, como os professores estão respondendo a esses desafios em sala de aula. E acho que o debate é a única maneira de enfrentar os desafios, porque o contexto é muito importante. Acho que a exposição de Walker em Saint Louis hoje é diferente do trabalho em si, independentemente das proposições de Walker no momento em foi feito ou de como ele o entendia. Acho que o ensaio de Glenn Ligon sobre Walker [2010] foi muito instrutivo na medida em que ele leu o trabalho de Walker como sintomático do fascínio da cultura branca por imagens de pessoas de cor. E foi uma leitura incrível e profunda.

Se você olhar para a história - você sabe, as leis de patentes têm apenas cerca de 150 anos - até um tempo relativamente recente, se você traduzisse um livro, você era considerado o autor desse livro na língua da tradução. Agora estamos em um momento histórico onde os regimes de mercado se encontram com os bens comuns e tentam regulá-los, com grande êxito, mas não com um controle total.

\section{JOAN KEE:}

Uma das coisas que me chamaram a atenção com relação à controvérsia sobre o Open Casket de [Schutz] é a certeza com que as pessoas se agarravam às suas opiniões, ao ponto de não haver absolutamente mais nenhuma dúvida. Se você odiasse a pintura, odiava a pintura e não havia mais o que conversar. Eu também vejo isso em termos de sala de aula. Este ano, pela primeira vez, todos os meus 
VERSÃO

alunos nasceram depois de 2000. E foi impressionante ver até que ponto todos eles simplesmente se recusaram a discutir essa polêmica porque, para eles, o chamado à discussão muitas vezes parecia pouco mais do que o ensaio de um conjunto limitado de afirmações de verdade. Em termos da discussão que realmente ocorre, será que ela é feita realmente para se chegar a um consenso ou uma resolução ou é discussão por discutir?

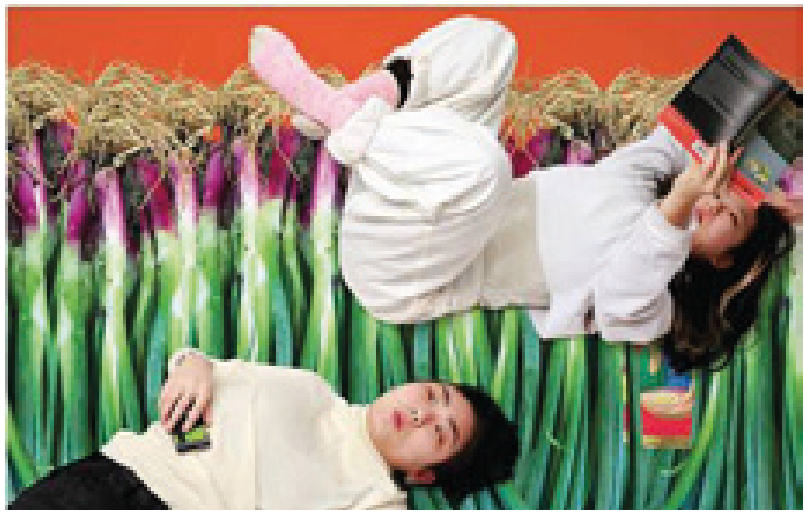

Figura 4. Yellow Jackets Collective, YJC, 2017, colagem digital com fotografias de Grace Na e Christal Sih. Fonte: <https:/l www. a $r$ t forum.com/inprint/ issue $=201706$ \&id $=68677$ >.

-las e deixar que morram?

\section{JACOLBY SATTERWHITE:}

\section{SALOME ASEGA:}

E como estamos usando ou instrumentalizando imagens nessas discussões? Já faz mais de vinte anos que temos o Google. Estamos acostumados com a velocidade em que as imagens nos chegam. E elas também parecem ter um período de vida mais curto - nós as discutimos e elas somem. Estamos reduzindo o ritmo e lendo imagens? Ou somos rápidos em falar sobre elas, descartá-

Mas não se sabe realmente se elas estão mortas, porque mesmo que seja uma cultura de memes, os memes às vezes são ressuscitados. Nós armazenamos essas coisas, e elas acabam sendo usadas para outros propósitos. Para ser sincero, não sei se as estamos descartando. Eu acho que nossos discos rígidos estão realmente cheios, e isso provavelmente está mudando a maneira como a cultura geral lida com as imagens.

\section{JOAN KEE:}

Eu concordo. Muitos dos meus alunos olham as imagens com uma postura do tipo "deixe eu acumular este arquivo maior e encontrar um algoritmo que possa ser replicado eternamente usando todas essas imagens que eu acumulei". Mesmo que sua atenção se mantenha por menos tempo, o banco de dados que eles usam é muito maior. E portanto, para eles, trata-se de uma infinita recombinação e da alteração das imagens, e não do uso intencional de imagens intactas tão fundamental para o legado do Pop e a estratégia da apropriação.

O pensamento deles, por sua vez, é transnacional e transcultural, influenciado por abordagens múltiplas e às vezes conflitantes à cópia e ao empréstimo. Um exemplo seria a atitude que muitos dos meus alunos da China têm em relação a shanzhai, uma palavra que antes era usada principalmente para se referir a atos criminosos de violação de direitos autorais. Hoje ela é mais usada para 
indicar a produção de código aberto destinada a ampliar a acessibilidade. Mas a facilidade com que agora é possível fazer apropriação física definitivamente faz parte do problema; para alguns, justifica nivelar a arte em um fluxo geral de comércio ou, mais problematicamente, para os outros, sugere que o uso de imagens sem referência ao contexto simplesmente deixou de ser um problema legítimo a se debater.

\section{GREGG BORDOWITZ:}

Mas existem diferentes mercados de arte e mesmo mundos da arte, certo? Então eu não sei se essas posições ou abordagens só podem ser desmembradas em categorias geracionais. Por exemplo, no mundo predominante da arte, ainda se valoriza o objeto artesanal, que tem um certo mercado. Não estou criticando qualquer método particular de se fazer arte, estou falando sobre as operações do mercado. A antiga noção marxista de desenvolvimento desigual é útil agora porque nos lembra de que não podemos presumir que haja desenvolvimento igual ou homogêneo em todos os lugares. Grande parte do mundo não tem acesso à internet, nem à tecnologia de que estamos falando. Aliás, a distribuição global de pessoas sem acesso à internet não corresponde com tanta facilidade a nações "desenvolvidas" ou "em desenvolvimento".

\section{HOMI BHABHA:}

Nada lhe impede de combinar tudo o que você quiser, assim como nada the impede de plagiar - até você ser pego. Você pode se apropriar do que quiser, mas só quando você for pego é vai surgir o problema. E, portanto, o próprio processo, por mais tecnologicamente aprimorado e geracionalmente aceito que seja, precisa de certas condições de aceitação ou critérios de julgamento.

Esses critérios não podem se basear simplesmente no tabu de apropriação ou no policiamento do que pode ou não ser apropriado, porque essas formas de apropriação e tradução continuarão a ser produzidas, gostemos ou não. De certa forma, elas são inerentes à nossa existência tecnológica.

E, portanto, a questão agora não se resume às condições de produção. A questão é: Quais são as condições de recepção? Quais são as "boas práticas interpretativas", se me permitem cunhar uma expressão? Essas práticas podem lidar com o sentido, com a moralidade, com implicações políticas, mas devem ser fundamentadas na crença da importância da convergência em vez do consenso, de reconhecer a diferença e os critérios de julgamento.

Mais uma vez, precisamos perguntar: quando juntamos essas diferentes citações ou imagens e que história elas estão contando? E você acha que essa história é útil? Ela está dizendo algo novo? É um pastiche ou puramente decorativa? Se a montagem realmente faz o que a montagem faz, que não é apenas 
colocar duas coisas uma ao lado da outra, mas sim produzir um tertium quid, produzir outra coisa que desloque cada uma dessas imagens ou textos e possa ser acumulada em um arquivo cada vez maior por meio da tecnologia, então a questão então passa a ser: quais são os critérios - interpretativos, políticos para se julgarem essas constelações? Quais são os critérios éticos de aceitação?

\section{AJAY KURIAN:}

Eu estou lendo um livro sobre migração, de Thomas Nail [The Figure of the Migrant, 2015] e parece apropriado à forma como estamos falando de imagens. Em vez de falar sobre apropriação, também podemos falar sobre a imagem migratória e as dinâmicas sociopolíticas que influenciam seus movimentos. Como a migração não é neutra, Nail fala em termos de nômade, bárbaro, vagabundo e proletariado, abordando, entre outras coisas, o estado de ilegalidade - não "ilegais", mas a condição em que tantas pessoas existem hoje, a de ilegalidade ou de sem-pátrias. E essa é uma relação de poder muito específica.

\section{MICHELLE KUO:}

Hito Steyerl fala sobre a imagem pobre, a imagem de baixa resolução que hoje viaja mais rápido e mais longe do que nunca, em maiores quantidades do que nunca, e que tem certa quantidade de poder. Quanto mais baixa resolução ela tiver, quanto mais empobrecida for, mais rápido ela viajará e mais poderosa será, em função de sua maior circulação.

Mas me impressiona que alguns dos debates que têm surgido sejam precisamente sobre parar essa circulação ou exigir que algumas imagens não proliferem nem circulem desse modo. E assim, essa é outra maneira de pensar sobre o movimento das imagens, para o bem ou para o mal. Jacolby, Ajay, Gregg, Salome - todo o seu trabalho e seu pensamento envolvem isso de alguma forma, sim.

\section{SALOME ASEGA:}

E temos que pensar sobre a diferença que surge quando as imagens circulam. A minha internet tem uma aparência diferente da sua, ainda que nós dois usemos o mesmo navegador. Enquanto isso, nossas máquinas estão nos aprendendo e estão desenvolvendo personalidades que são como as nossas.

\section{JACOLBY SATTERWHITE:}

Não é assustador quando um aplicativo aparece enquanto você está falando ao telefone, e está relacionado a algo que você disse em voz alta?

\section{SALOME ASEGA:}

Sim. É escuta, mesmo! 


\section{JACOLBY SATTERWHITE:}

Eu vi anúncios no Facebook que têm a ver com a minha conversa falada. Ou se eu pesquisar algo no Instagram, ele pode aparecer no meu e-mail.

\section{MICHELLE KUO:}

Isso é que é apropriação, uma loucura!

\section{GREGG BORDOWITZ:}

Acho que essa é a ansiedade que está na base desta conversa: essa cultura de vigilância em que vivemos, que funciona através da apropriação, do fato de que a capacidade de apropriação está embutida nas tecnologias que usamos todos os dias.

E a intransigência das posições dentro dos debates atuais é sintoma de uma ansiedade muito maior sobre viver em um país que está profundamente dividido e administrado por um regime neofascista.

O presidente e seus assessores são modelos de um certo tipo de intransigência. 0 que tenho medo é da política dos testes para por as pessoas à prova, mesmo que o objetivo seja algo que eu possa apoiar. Por exemplo, divulgar os nomes dos membros do conselho do museu que apoiaram o Trump durante a eleição - aonde isso vai levar? É uma estratégia limitada e perigosa para a esquerda.

Eu me lembro de que no movimento LGBTQ, divulgar nomes e constranger foram estratégias venenosas para a atmosfera de ativismo queer porque levaram a uma política de testes nos quais se passava ou não. E há um velho ditado na esquerda: "Quando o inimigo não está na sala, praticamos uns nos outros". Esse não é um futuro que me interesse.

Eu tenho muito medo disso. Eu já vi isso. Eu vi isso nos movimentos de que participei, no movimento ativista da AIDS e em outros movimentos de esquerda. Eu abandonei a política sectária para participar do ativismo da AIDS, porque a AIDS nunca foi um movimento político de uma questão única - a epidemia tocou em todas as questões e o ativismo da AIDS não era sectário, ao contrário da esquerda tradicional do final dos anos 70 e início dos anos 80 , que era assolada por lutas internas terríveis. E agora eu sinto isso novamente no tipo de política que está surgindo, e me assusta.

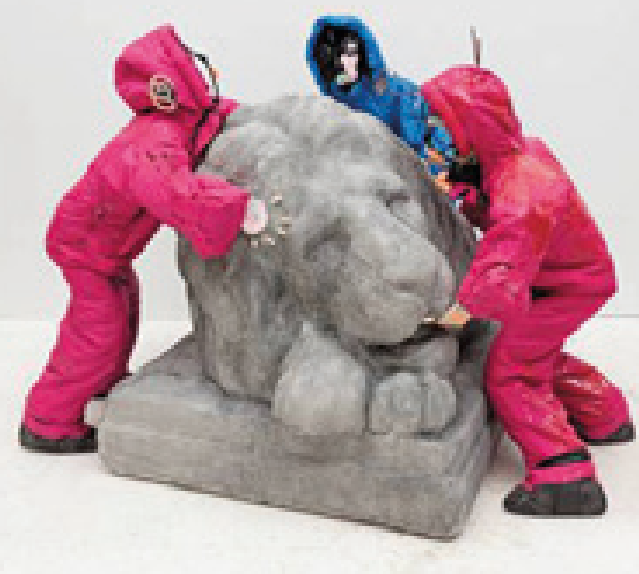

Figura 5. Ajay Kurian, Here to Help, 2016. Sacos de dormir que se vestem, fio de alumínio, fita adesiva, argila epóxi, cereais impressos 3-D, corrente de plástico, folhas falsas, areia, espuma, concreto, Rockite, tinta, ferragens, varas de incenso, poliuretano, $40 \times 66 \times 52$ ". Fonte: $<$ https://www. a r t forum.com/inprint/ issue $=201706$ eid $=68677$ >. 


\section{HOMI BHABHA:}

O que entendemos como política sectária não é tanto que o inimigo esteja fora da sala, e sim duas outras coisas: em primeiro lugar, quando o inimigo é complexo demais para criar solidificação ou solidariedade entre aqueles que estão contestando seu poder; em segundo, quando o próprio inimigo é complexo internamente, contraditório - cedendo poder em um ponto, retendo-o em outro. Não é que o inimigo esteja fora da sala, e sim que, quando ele está sentado dentro da sala, não se pode entender quem é o inimigo ou quais são seus diferentes rostos dentro da sala.

Diante desse tipo de complexidade, os grupos de oposição tendem enfrentar uns aos outros, devido a problemas de estratégia ou compreensão. 0 truque é garantir que você entenda que existe uma linha que você não pode ultrapassar sem colaborar com os poderes aos quais quer se opor.

\section{SALOME ASEGA:}

Depois da eleição, eu tenho passado muito tempo pensando em que tipos de estruturas de responsabilização precisam ser criados para quando eu pisar na bola ou quando pessoas ao meu redor fizerem isso. $E$ isso não significa necessariamente constranger, mas deve haver pelo menos algum tipo de código ou conjunto de regras.

\section{GREGG BORDOWITZ:}

Eu concordo - tem que haver uma maneira de criticarmos uns aos outros e nos responsabilizarmos. Mas estou pensando em como organizar uma discussão crítica na qual possamos nos deparar com momentos dolorosos de diferença e superá-los.

\section{AJAY KURIAN:}

Agora, nas redes sociais, quando divulgamos algo, estamos colocando um ponto final - como em "fim da discussão" - no fim de cada coisa que dissemos. Houve uma época em que eu me envolvia nessas brigas de Facebook, e cada vez que eu construía um comentário, pretendia que fosse a última palavra; não era dialógico. E eu parei de fazer isso. Eu pensei: isso é ridículo. Estou alimentando uma habilidade tóxica.

\section{JACOLBY SATTERWHITE:}

Ensina a digitar mais rápido.

\section{AJAY KURIAN:}

E ensina a vomitar no próprio cérebro. É uma facilidade nociva na qual as pessoas estão ficando realmente boas. Não é uma crítica, porque não há possibilidade de entrar em diálogo com a outra pessoa. Ainda é a produção de si mesmo contra a produção de outra pessoa. 


\section{MICHELLE KUO:}

E é claro que há muitas pessoas que só viram o Open Casket no Instagram ou na internet; elas nunca viram no contexto da exposição. E tem muita gente que viu a exposição e não tem ideia de que essa polêmica esteja acontecendo. Então eu acho que as formas pelas quais uma imagem ou uma obra são arrancadas isoladamente do seu contexto, o que parece inevitável agora, exige novas formas de comunicação. Se tudo o que resta do discurso é uma série de comentários que não são dirigidos a ninguém em particular, nunca poderemos ter sentido intersubjetivo, ou seja, entender outra pessoa, entender sentidos em um texto ou em uma imagem, entender algo fora de nós mesmos. A única opção que resta para a arte é a autobiografia. Isso é absurdo, mas como se começa a pensar em outros modelos de conversa ou interação? É claro que se pode resistir a essas estruturas, mas será que existem alternativas?

\section{JOAN KEE:}

Uma possibilidade pode ser se afastar das discussões baseadas em direitos e, em vez disso, considerar quais são as nossas obrigações e para com quem. É claro que isso levanta a questão de quem vai administrar essas obrigações ou, ou seja, de autoridade e aplicação. Mas pelo menos estimula a pensar na participação como um reconhecimento de dívida e não como exercício de direitos. Isto é, deve-se fazer um trabalho preliminar no registro de atitude: humildade em vez de presunção de onisciência. Talvez seja necessário promover momentos deliberados de fracasso.

\section{HOMI BHABHA:}

Dito de outra forma: como representamos de maneira justa os pontos de vista que contestamos ou rejeitamos ao fazer o melhor que podemos para garantir que nossos oponentes reconheçam que seus pontos de vista foram representados e avaliados com justiça, mesmo quando recebem questionamentos contraposições devastadoras? Partindo de histórias, crenças e valores diversos, tem que haver uma visão que enfatize a importância da convergência e que nos liberte para seguirmos nossos próprios caminhos.

A convergência é movida por processos, e o "devido processo" no debate exige o que eu chamo de boa prática interpretativa. Como uma comunidade define isso sem aceitar a noção de um livre mercado de ideias, sabendo que nada é "livre" de custos, nada sai de graça?

\section{GREGG BORDOWITZ:}

Eu acho que deve começar pelo reconhecimento de que estamos atomizados como nunca estivemos, e que todos estamos olhando várias telas e acompanhando a história de todas as maneiras diferentes. E assim, o trabalho da educação é estabelecer um terreno em que o aluno possa conceituar sua subjetividade 
como um eu múltiplo, usando uma constelação de histórias, ideias e convicções, referências que podem abranger a história da arte, mas que também incluirão outros tipos de formação de habilidades e trajetórias históricas.

Concordo com você, Jacolby, em que a apropriação terá um formato muito diferente no futuro e isso pode acontecer de acordo com visões muito diferentes sobre identidade. Novas formações identitárias surgem historicamente. Por exemplo, "pessoas com AIDS" é um exemplo relativamente recente de uma identidade nova que atravessa limites estabelecidos para criar novos públicos de interesse.

\section{AJAY KURIAN:}

Pensando sobre essa atomização, é curioso porque, em certo sentido, a única coisa que nos liga agora é o produto. Todo mundo tem um iPhone, todo mundo tem alguma tecnologia definidora. "Nós temos isto" é a nossa inteligência social agora, uma forma compartilhada de conhecimento. Para os artistas, tem sentido querer se tornar Katy Perry ou um superastro, porque, para passar a fazer parte de um sentido social compartilhado, você precisa se transformar em produto.

\section{GREGG BORDOWITZ:}

Como se cria um contexto onde se possa ter uma sala cheia de pessoas envolvidas em todas essas práticas diferentes e onde as diferenças possam ser negociadas? Parece valer a pena voltar à noção de poética de Aristóteles como disciplina ou prática que molda a forma como se juntam as coisas. A composição se torna o conceito comum através do qual todos podemos conversar uns com os outros em diferentes mídias. Pode ser um movimento pedagógico conservador, mas talvez seja uma maneira de estabelecer uma linguagem comum para a conversa.

\section{JACOLBY SATTERWHITE:}

Estou surpreso que a Rachel Dolezal não tenha aparecido hoje. [Ri.]

\section{SALOME ASEGA:}

Pare!

\section{JACOLBY SATTERWHITE:}

Eu estou obcecado com ela.

\section{AJAY KURIAN:}

É uma espécie de incômodo para você?

\section{JACOLBY SATTERWHITE:}

Eu gosto das pinturas negras dela. Eu adoro que ela faça arte. 


\section{AJAY KURIAN:}

Eu não sabia disso.

\section{JACOLBY SATTERWHITE:}

Ela tinha um mercado. Aquelas pinturas do J. J. de Good Times. As pinturas dela são como pinturas do orgulho negro que você pode ver em uma loja coreana de produtos para o cabelo.

\section{GREGG BORDOWITZ:}

Eu entendo por que a Rachel Dolezal foi tão perturbadora. A minha política identitária, formada nos anos 80 , reconhece a autodeterminação como o princípio mais importante. Os grupos de mulheres, as pessoas que ocupam posições minoritárias, principalmente as posições oprimidas, tiveram e têm o direito de se organizar e controlar os espaços onde definem os termos da discussão.

\section{MICHELLE KUO:}

Mas esse tipo de controle é problemático. Mais uma vez, pode acabar reproduzindo as próprias estruturas de supressão que marginalizam e reprimem.

\section{HOMI BHABHA:}

Em todos os contextos de sofrimento, há sempre a posição de testemunhar e há a posição de atestar. Parece-me que, se você disser que "somente quem sofreu ou foi oprimido pode falar pelos oprimidos" se corta a possibilidade de construir uma coalizão mais ampla de pessoas e estruturas que sejam contrárias às formas de opressão e possam defender a liberdade ou o bem comum.

Por exemplo, a crítica de James Baldwin a Elijah Muhammad [e à Nação do Islã] foi: "Já temos problemas suficientes para criar uma nação. Será que realmente queremos duas?" Ou sua outra grande declaração: "Não se pode resolver o problema dos afroamericanos sem os brancos americanos. Não se pode resolver esse problema, e tampouco se pode transferi-lo para algum Pan-Africanismo".

\section{MICHELLE KUO:}

Eu interpreto a demanda que diz que "apenas uma pessoa certificada da raça $X$ pode falar por essa raça" como um retorno a uma fanta-

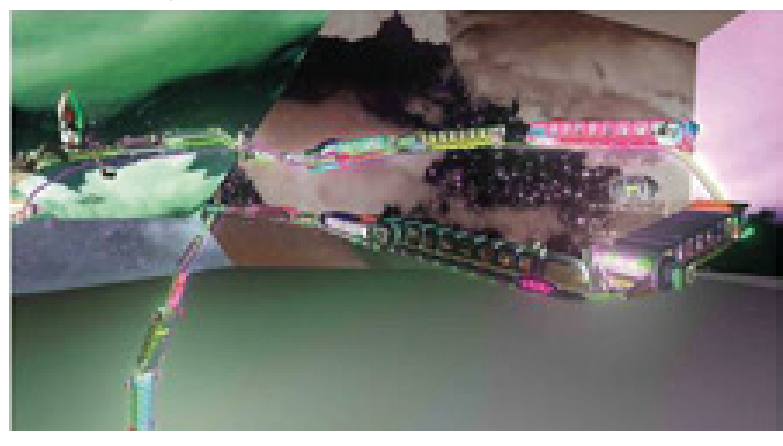
sia de pura subjetividade; o ponto final é o solipsismo. Como é que podemos aprofundar a disseminação do pensamento intersubjetivo, das imagens, das ideias, independentemente do lugar de onde elas vieram ou de quem acha que
Figura 6. Jacolby Satterwhite, $P i$, 2013, Impressão C-print, 30×53". Fonte: <https://www. a r t forum.com/ inprint//issue=201706Eid=68677 >. 
as possui, enquanto garantimos que a disseminação seja feita de maneira para usar um termo anódino - produtiva em vez de sofrida?

\section{GREGG BORDOWITZ:}

Acho que eu diria que é nos organizando. É a isso que eu estou direcionando a minha atenção agora. Primeiro, tem que haver uma maneira de pessoas de diferentes identidades se aliarem. Eu defendo um ideal de política de coalizão organizado entre ativistas, com a finalidade de compartilharmos recursos e nos apoiar mutuamente, arriscando-nos uns pelos outros quando necessário. Ainda estou procurando modelos como esse.

Ouvi e adotei o que Stuart Hall nos disse em 1991, no Studio Museum, no Harlem: que devemos avançar sem as garantias de essencialismo. E agora não sei o que aconteceu com aquele momento.

\section{HOMI BHABHA:}

Nós todos também, e tínhamos razão em fazê-lo. Mas estamos no meio de um apagamento feroz das vidas, experiências e histórias dos marginalizados, dos oprimidos, das minorias. É uma história antiga, mas também nova. Os imigrantes sem documentos são imediatamente identificados como criminosos apenas porque atravessam uma fronteira - procurando trabalho e sendo absorvidos na economia informal - mas, de repente, eles se tornam ração para alimentar a xenofobia populista e o racismo. Quando ocorrem esses apagamentos, há um desejo compreensível de se apegar a algo que seja "próprio", que não esteja sendo tirado de você ou imposto a você pelo poder e a rentabilidade alcançada à sua custa. Nesses momentos, as pessoas se tornam possessivas - infelizmente, até mesmo "essencialistas" - como se fosse para se defender de "fundamentalismos" hegemônicos com alguma identidade ou crença fundacional alternativa, com algo que pertence a você e que está em perigo e vulnerável. E isso levanta a complexa e polêmica questão da apropriação. 